\title{
Multiple splenic artery aneurysms in non-cirrhotic hepatic fibrosis
}

\author{
Barun Bagga, Chandan Jyoti Das
}

Radio diagnosis, All India Institute of Medical Sciences, New Delhi, India

Correspondence to Dr Chandan Jyoti Das, docchandan17@gmail.com

Accepted 9 April 2019

\section{DESCRIPTION}

A 40-year-old female patient, a known case of non-cirrhotic hepatic fibrosis (NCHF), came for follow-up to our clinic. She had a previous history of recurrent episodes of abdominal pain with haematemesis and melena. The patient had no episodes of jaundice. Ultrasonography and liver biopsy were done at the time of her earlier evaluation a year ago. Dilated patent spleno-portal axis with normal liver size, outline and echo texture and moderate splenomegaly were seen on ultrasonography. Liver biopsy done showed absence of regenerative nodules with no features of cirrhosis. Complete blood count, metabolic panel including the liver function tests and $C$ reactive protein were normal at present. Viral serologies for hepatitis B and C and autoimmune markers including antinuclear antibody were negative. She had never consumed alcohol and was on no medication apart from propranolol for prophylaxis against upper gastrointestinal (UGI) bleed. Serum iron and ferritin were within normal limits. There were no clinical or imaging signs of chronic pancreatitis. Based on the moderate splenomegaly, dilated patent spleno-portal axis, normal liver function tests and absence of cirrhosis on biopsy, the diagnosis of NCHF was made, which is a relatively common cause of portal hypertension in a low/ middle-income country like India. UGI endoscopy was done previously when the patient had haematemesis at an outside hospital, which revealed isolated gastric varices for which endoscopic band ligation was performed. The exact endoscopic details were not available for this patient. She has remained asymptomatic thereafter.

At present, the patient had come for ultrasound Doppler follow-up. Ultrasound revealed the presence of dilated spleno-portal axis and multiple collaterals as seen previously. In addition, the splenic artery appeared tortuous with multiple aneurysms

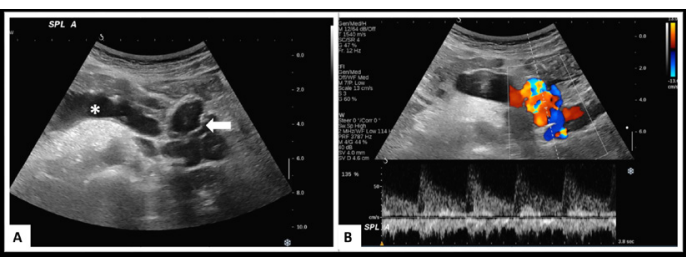

(C) BMJ Publishing Group Limited 2019. No commercial re-use. See rights and permissions. Published by BMJ.

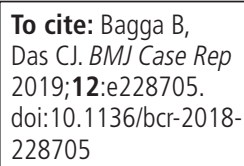

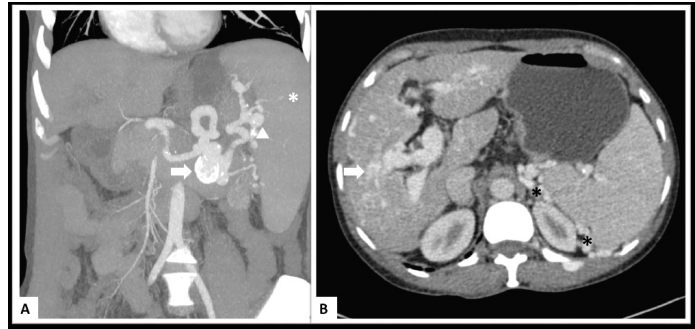

Figure 2 (A) Arterial phase coronal reformatted maximum intensity projection of CT showing splenomegaly (marked by asterisk) and dilated tortuous splenic artery with multiple aneurysms arising from the splenic artery (marked by arrows) and its branches (marked by arrowheads), many showing wall calcifications. (B) Axial portal venous phase image showing dilated main, right and left portal veins with pruning of the distal portal vein branches (marked by an arrow) and multiple extrahepatic collaterals (marked by asterisk).

(figure 1). Multiphasic contrast-enhanced CT was then performed to delineate the anatomy. Arterial phase images showed the presence of splenomegaly with dilated tortuous splenic artery with multiple saccular aneurysms arising from the middle and distal segments of the splenic artery and its branches (figure 2A), the largest of which measured less than $2 \mathrm{~cm}$ in maximum dimension. Many of the aneurysms also showed peripheral wall calcifications. Portal venous phase images showed dilated main, right and left portal veins with pruning of the distal portal vein branches and multiple extrahepatic collaterals with normal liver size and attenuation (figure 2B). These features were consistent with the development of multiple splenic artery aneurysms in a setting of NCHF likely secondary to portal hypertension.

Splenic artery aneurysms are rare in incidence, and only a few case reports have shown association with NCHF. However, despite the rarity, they are immensely important to detect on imaging as they are clinically asymptomatic and have a propensity for spontaneous rupture and bleeding. ${ }^{1}$ These are considered to be a result of altered haemodynamics due to portal hypertension. The management of NCHF entails managing the UGI bleed, which is the major complication, with endoscopic sclerotherapy or variceal band ligation. ${ }^{2}$ The treatment options of splenic artery aneurysms in the setting of portal hypertension include conservative follow-up, endovascular treatment or surgical ligation of the aneurysm. The size of the splenic artery aneurysm less than $2 \mathrm{~cm}$ and the presence of dense calcification 
on CT are considered favourable signs with less risk of rupture. However, follow-up with high-resolution cross-sectional imaging is essential to imperative. ${ }^{3}$ In our case, since the patient is currently asymptomatic and there are multiple aneurysms, many showing calcification, with the largest aneurysm less than $2 \mathrm{~cm}$ in size, we decided to keep this patient for close follow-up using ultrasonography in 3 months interval apart from the routine clinical and laboratory tests which are performed 6 monthly s recommended for NCHF. Regarding the isolated gastric varices

\section{Learning points}

Splenic artery aneurysms are rare but life-threatening complications of non-cirrhotic hepatic fibrosis and are usually asymptomatic.

- Therefore, follow-up of these patients with ultrasound Doppler is imperative, despite the lack of obvious symptoms.

- Large size of the splenic artery aneurysm and lack of wall calcifications on CT are predictors of the risk of rupture and dictate management decisions. treated previously with endoscopic variceal ligation, the current study suggests better results with endoscopic glue injection with $\mathrm{N}$-butyl-cyanoacrylate, which would be considered if the patient has an UGI bleed. ${ }^{4}$

Contributors CJD had the idea for the article. He is the guarantor of the article. BB was responsible for the literature search, investigations of the patient and was the writer of the report.

Funding The authors have not declared a specific grant for this research from any funding agency in the public, commercial or not-for-profit sectors.

Competing interests None declared.

Patient consent for publication Obtained.

Provenance and peer review Not commissioned; externally peer reviewed.

\section{REFERENCES}

1 Mishra PK, Saluja SS, Sharma AK, et al. Management of splenic artery aneurysm associated with extrahepatic portal vein obstruction. Hepatobiliary Pancreat Dis Int 2012;11:330-3.

2 Sarin SK, Kapoor D. Non-cirrhotic portal fibrosis: current concepts and management. J Gastroenterol Hepatol 2002;17:526-34.

3 Lakin RO, Bena JF, Sarac TP, et al. The contemporary management of splenic artery aneurysms. J Vasc Surg 2011;53:958-65.

4 Khanna R, Sarin SK. Non-cirrhotic portal hypertension - diagnosis and management. Hepatol 2014;60:421-41.

Copyright 2019 BMJ Publishing Group. All rights reserved. For permission to reuse any of this content visit https://www.bmj.com/company/products-services/rights-and-licensing/permissions/

BMJ Case Report Fellows may re-use this article for personal use and teaching without any further permission.

Become a Fellow of BMJ Case Reports today and you can:

- Submit as many cases as you like

- Enjoy fast sympathetic peer review and rapid publication of accepted articles

- Access all the published articles

- Re-use any of the published material for personal use and teaching without further permission

For information on Institutional Fellowships contact consortiasales@bmjgroup.com

Visit casereports.bmj.com for more articles like this and to become a Fellow 